\title{
Reinsurance, Profitability and Insurability
}

\author{
by Harald Bohman*
}

\section{Summary:}

It is observed that there is a certain similarity between reinsurance and borrowing money among friends. There are no written documents to prove that you got a liability because you received an amount of money from your friends. Reinsurance is a question of trust and confidence. Even so you need an instrument to measure and compare different reinsurance contracts from the point of view of risk. Such an instrument is demonstrated in the paper. The most risky contracts must be placed with your most reliable reinsurance partners. There are also contracts which are so risky that they cannot be placed on the market.

It has often been said in our trade that there are no bad risks. There are only bad premiums. Even if you have heard this old saying many times you know intuitively that it is essentially wrong. There are bad risks in reinsurance and you should try to avoid them.

In this paper we are going to discuss insurability from the point of view of reinsurers and how to recognize a risk as uninsurable.

First thing we need is a model according to which profitability can be measured. This model must be so general that it includes all different types of reinsurance.

We start out by thinking of two insurance companies, the ceding company $\mathrm{C}$ and the reinsurance company $\mathbf{R}$. These two companies have decided to do reinsurance business together. First thing to do is to set up a reinsurance contract.

The reinsurance contract is valid for one calendar year at a time. It is renewed at the end of each calendar year if both parties agree to do so. If $\mathrm{C}$ or $\mathrm{R}$ or both find that the contract should not be renewed it will not be in force as from the beginning of next year and no further payments are made under the contract.

If the contract is in force during calendar year $n$ then $\mathrm{R}$ has to pay an amount $X_{n}$ to $\mathrm{C}$ at the end of year $n . X_{n}$ is defined in the contract.

If the contract is in force during calendar year $n$ then $C$ has to pay a reinsurance premium $P_{n}$ to $\mathrm{R}$ at the end of year $n$. There is an algorithm, presented in the contract, according to which $P_{n}$ has to be calculated.

\footnotetext{
* Skandia Insurance Company.
} 
$X_{n}$ may be defined in many different ways. Let us mention just a few examples:

$X_{n}$ is the sum of a certain fraction of the claim payments and the same fraction of the net increase of the technical reserve.

$X_{n}$ is the sum of the claim payments and the net increase of the technical reserve for a certain portfolio.

Certain claims are considered to be large because they are in excess of a certain limit and $X_{n}$ is defined as the sum of such costs of claims in excess of the said limit. By cost of claims is then meant payments and net increase of the technical reserve.

$X_{n}$ is the cost of claims as defined in a surplus reinsurance contract.

The above examples illustrate how different types of reinsurance give rise to different definitions of $X_{n}$. Note however the following important difference between many reinsurance contracts which are used in practice and the contract assumed to exist between $C$ and $R$. In the last-mentioned contract there are no fund deposits. If the contract is terminated there are no further payments to be made by $\mathrm{R}$ to $\mathrm{C}$. Consequently $\mathrm{R}$ has no technical reserve as a result of his contract with $C$. This is so because the whole of the technical reserve stays with $C$. As soon as there is a net increase of the technical reserve the corresponding part which is related to $R$ is payed by $R$ to $C$ as part of his claim payments to $C$.

This is not the method normally used in practice. In order to be able to use the reinsurance method used between $\mathrm{C}$ and $\mathrm{R}$ you have to undertake a few modifications in your traditional reinsurance schemes. The net increase of the technical reserve must be included in the claim payments from $\mathrm{R}$ to $\mathrm{C}$ whether the technical reserve is deposited or not. If the technical reserve is deposited partly or in full the interest on such deposits is included in the premium to be paid by $C$ to $R$. To the extent that the technical reserve is not deposited interest earned by $R$ on such reserve is also dealt with as a premium paid by $C$ to $R$. This case is dealt with as if $R$ has a debt to $\mathrm{C}$ equal to the technical reserve not deposited with $\mathrm{C}$.

Up to now we have been discussing various modifications in existing reinsurance schemes intended to adapt them to the reinsurance method used between $C$ and $R$. These modifications could be described as modifications in the book-keeping and they have little or no influence on the economy of the reinsurance contract. We now turn however to an important difference between traditional reinsurance methods and the method used by $\mathrm{C}$ and $\mathrm{R}$. It has already been observed that there is in the contract between $\mathrm{C}$ and $\mathrm{R}$ an algorithm according to which the reinsurance premium has to be calculated. Such an algorithm is not found in traditional reinsurance contracts.

Before the algorithm is presented a few words might be helpful to explain the background to the algorithm.

When payments are made between two parties it can always be recommended to keep an account in order to follow the outcome of such transactions. In this case $\mathbf{R}$ keeps such an account and the balance on the account at the end of year $n$ is denoted by $G_{n}$. R adds to the account premiums be receives from $\mathrm{C}$ and he deducts from the account claims which he pays to $\mathrm{C}$. He also adds interest to the account at the rate $j$. This rate of interest has two different values, one lower value is used when $G$ is positive and one higher value is used when $G$ is negative. These different rates correspond to the different rates of interest which are used when you borrow money from and when you lend money to a bank. 
In the algorithm there is also found a parameter $c$ which shall take a value between 0 and 1 . This parameter controls the smoothing effect of the scheme. The larger $c$ is the less influenced is the premium by variations in $X$. At the same time however variations in $G$ become larger.

The premium formula is essentially based on a mean value $\bar{X}$ of $X$. The system is open to random variations and you must get into the system some device which can help you to control such variations. This device is in fact the second term of the premium formula.

We are now ready to present the algorithm. It looks like this:

$$
\begin{aligned}
& \bar{X}_{n}=c \bar{X}_{n-1}+(1-c) X_{n} \\
& P_{n}=\bar{X}_{n}+(c-1-j) G_{n-1} \\
& G_{n}=(1+j) G_{n-1}+P_{n}-X_{n} \\
& j \quad=j^{\prime} \quad \text { if } G_{n-1}<0 \\
& j^{\prime \prime} \text { if } G_{n-1}>0
\end{aligned}
$$

It is very common in reinsurance contracts that the reinsurer wants an upper limit to be set out in the contract above which he is not willing to participate even if the actual claim is higher. In the present case the corresponding limitation of the liability is obtained by prescribing a lower limit $L$ below which $G$ is not allowed to fall. Should such a situation arise in year $n$ then the actual $X_{n}$ has to be replaced by a fictitious $X_{n}^{\prime}$ calculated according to the following formula:

$$
X_{n}^{\prime}=G_{n-1}+\bar{X}_{n-1}-L / c
$$

Some manipulations with the formulas lead to the following expression for $G$ :

$$
G_{n}=c G_{n-1}+\bar{X}_{n}-X_{n}
$$

This formula tells you that $G$ is a stationary process under stationary conditions. This is the same as to say that $G$ fluctuates around 0 if there is no trend development going on.

The advantage with the reinsurance scheme agreed upon between $\mathrm{C}$ and $\mathrm{R}$ is that both parties have agreed upon claim payments and premium payments and that both parties will be satisfied with the outcome of the reinsurance business if they follow the scheme.

In traditional reinsurance contracts there is no algorithm according to which the premium is calculated. It is often hard to tell how the premiums are actually calculated. Suppose however that we accept the premiums and the claim payments as they are. We can then calculate an account $G$ and include interest as described above. We know that if we have applied premiums calculated according to the algorithm then $G$ will stay around 0 . It will then be interesting to see if the actual premiums will lead to the same result, namely that $G$ stays around 0 . If not it might be time for the two parties to discuss the reinsurance premium.

From what has been said above we can now draw the conclusion that if the claim process $\left\{X_{n}\right\}$ is given you can always define a premium process $\left\{P_{n}\right\}$ and that these two processes together lead to an equitable reinsurance scheme. This is mathematically true but there is also a human side of the problem which must now be mentioned. 
It can be demonstrated that the variance of $G$, calculated under the assumption of stationary conditions, is equal to the variance of $X$ times the following factor:

$$
\frac{2 c^{2}}{(1-c)(1+c)^{3}}
$$

This formula tells you, as could be excepted, that the larger $c$ is the larger will also the variance of $G$ become. If the ceding company is asking for high degree of smoothing then the reinsurer is open to the risk of heavily fluctuating $G$.

Suppose that for some reason or other $g$ has reached a very low negative value. Expressed differently the ceding company has made a large profit from the reinsurance contract. It is then of course a temptation for him to cancel the reinsurance contract and keep the profit he has made. If the profit is large enough he might find it more profitable to keep the profit and lose his reinsurance partner.

Suppose that for some reason or other $G$ has reached a large positive value. Again there is a temptation to cancel the reinsurance contract. But this time it is the reinsurer who has the temptation to do so.

We now come to the conclusion that the process will run smoothly as long as the variations of $G$ remain moderate as compared to the size of $P$ and $X$. If the two parties really rely upon each other they might accept a larger variation of $G$ than they will be able to accept if they do not trust each other as much.

Reinsurance is a question of confidence and trust. If the parties have unlimited trust in each other they can do reinsurance business together even in the case of claim processes with a large variance. If they have less confidence in each other they have to study the variance of $X$, the degree of smoothing as expressed by the size of $c$ and the variation of $G$ which they are willing to risk.

Insurability becomes a question of confidence. It is like lending money to friends. The more confidence you have in your friend the larger is the amount you are willing to lend him. In the case of reinsurance you have however to look out for the size of the variance of $G$ rather than the amount of money your friend wants to borrow from you. 